\title{
artigo
}

1. Introdução;

2. Estrutura e valores organizacionais;

3. Modelo organizacional e criatividade cientifica; 4. Caracteristicas do papel de administrador da pesquisa;

5. Papéis de administração da pesquisa na Embrapa,

6. Conclusão.

\section{Administracão da pesquisa: organização e papéis ocupacionais}

\begin{abstract}
Jairo Eduardo Borges-Andrade
Pesquisador e assessor do Departamento de Recursos Humanos/Embrapa, em Brasilia, desde 1979; Ph.D em sistemas instrucionais, pela Florida State University,
\end{abstract} Tallahassee, em 1979.

\section{INTRODUÇÃO}

Uma organização pode ser definida pelo seu produto ou pelo conjunto de produtos que têm similaridades entre si (Hage, 1980). Instituições de pesquisa, como a Empresa Brasileira de Pesquisa Agropecuária (Embrapa), não fogem a esta regra. No caso da Embrapa, esses produtos são os conhecimentos $e$ as tecnologias agropecuárias gerados em função de uma necessidade global e de demandas específicas advindas da sociedade brasileira.

$\mathrm{Na}$ medida em que aqueles produtos podem ser identificados, é possível caracterizar a organização e, por conseguinte, seus objetivos, sua estrutura e suas funções. Finalmente, podem ser definidos os papéis ocupacionais dos indivíduos que nela atuam, isto é, podem ser definidos, segundo Quirino e Pereira (1980), os conjuntos de prescrições comportamentais relacionados à produção e/ou à distribuição de bens e serviços. No presente caso, trata-se dos conjuntos de prescrições referentes aos administradores da pesquisa, reconhecidos como tal pelą Empresa. A partir destas prescrições, podem ser deduzidas as habilidades que os referidos administradores devem possuir ou adquirir, a fim de que possam desempenhar seus papéis ocupacionais.
Os produtos, contudo, podem ser tantos, ou tão distintos, que se torna difícil caracterizar uma organização utilizando-se estes critérios. Exemplos deste caso são as multinacionais, as grandes empresas nacionais (públicas ou privadas) que funcionam em sistemas de holding e a administração pública federal, que são categorizados por Hage (1980) como multiorganizações. As suas estruturas organizacionais são analisadas pela literatura a um nível por ele denominado "macro".

A Embrapa parece fazer parte do primeiro grupo Ela tem um conjunto de produtos claramente definido e um sistema de recursos humanos próprio, no qual três grupos de papéis são definidos em função de seus produtos: os de administração geral, de apoio à pesquisa e técnico-científicos. A Empresa gere ainda os recursos financeiros a ela alocados e tem autonomia para determinar, planejar, executar e avaliar suas ações - programas e projetos de pesquisa. Assim, a Embrapa tem um processo autônomo próprio de produção. Ele é reproduzido en escala menor em cada uma de suas unidades de pesquisa. Desta maneira, ela parece reunir as condições necessárias para ser analisada ao nível "meso" (Hage, 1980) e ser chamada uma organização. Em seguida, serão tecidas considerações sobre o caráter geral desta organização.

\section{ESTRUTURA E VALORES ORGANIZACIONAIS}

As instituições de pesquisa podem ser classificadas, quanto à sua organização social e à natureza do trabalho científico que desenvolvem, em três modelos típicos: "república da ciência", "progresso técnico", e "tecnoburocracia" (Schwartzman, 1981).

O primeiro modelo, também chamado de ciência acadêmica por Long e McGinnis (1981), valoriza o conhecimento pelo conhecimento. A qualidade da sua produção é aferida por consenso de uma determinada comunidade científica estratificada e possuidora de regras bem definidas de acesso e exclusão a ela. $O$ desempenho do cientista é recompensado por meio de prestígio acadêmico, advindo da ampla difusão, na própria comunidade, das informações por ele geradas.

Ao contrário da ciência acadêmica produzida por este primeiro modelo, o modelo de "progresso técnico" geralmente resulta em ciência aplicada. Ele vê o objetivo da pesquisa como sendo o de resolver, por meio técnico, os problemas econômicos e sociais da sociedade. A qualidade do produto assim obtido é avaliada pela sua aceitação no mercado, sendo o pesquisador recompensado pelo valor social e/ou financeiro da venda deste produto. Neste segundo modelo, a ênfase dada à livre circulação de informações é substituída pela lógica pragmática dos negócios, que muitas vezes obriga ao atraso na difusão, até que a tecnologia gerada seja devidamente patenteada (Long e McGinnis, 1981).

A demanda qualitativa e quantitativa de conhecimentos e tecnologias, feita pela sociedade contemporânea, colocou novos problemas para a pesquisa. Estes problemas deixaram de ser passíveis de resolução ao nível individual, por cientistas trabalhando isoladamente, para só o serem através do esforço organizado de equipes interdisciplinares de pesquisadores, conforme as define Quirino (1981). Surgiram, portanto, as grandes organiza- 
ções técnico-científicas, muitas vezes financiadas pelo dinheiro público, com a proposta de atender às crescentes e complexas necessidades da sociedade.

Esta evolução resultou no terceiro modelo de atividade científica, ao qual Schwartzman (1981) denomina "tecnoburocracia". O valor básico deste modelo é o crescimento e fortalecimento da própria organização. $\mathrm{O}$ produto do trabalho do cientista tem sua qualidade aferida em relação direta com.os objetivos e os valores definidos pela própria organização e não com os do mercado ou da comunidade científica. Este produto é sempre de propriedade da organização, que em troca recompensa o pesquisador, auferindo-lhe crescente poder burocráticoorganizacional interno e externo.

Os três modelos descritos por Schwartzman podem coexistir numa mesma instituição de pesquisa. $\mathrm{Na} \mathrm{Em}$ brapa, predomina o terceiro tipo de orientação. Contudo, podem ser também nela encontradas características dos outros dois modelos. Desta forma, o axioma fundamental das "tecnoburocracias", que é o de crescimento e fortalecimento organizacional, convive na Embrapa com o do modelo de "progresso técnico", que é o da utilidade econômica e social (ou talvez um seja o meio para alcançar o outro). Em conseqüência, a qualidade do trabalho do pesquisador na Embrapa é aferida em relação aos objetivos da Empresa (modelo de "tecnoburocracia"). Estes, por sua vez, são determinados através do pressuposto da incorporação dos resultados à rotina do sistema de produção agropecuária (modelo de "progresso técnico").

O sistema de recompensas existente na Embrapa está intrinsecamente baseado no poder burocrático-organizacional (terceiro modelo) delegado pela Empresa ao pesquisador considerado produtivo. Exemplos dessas recompensas são o aumento da disponibilidade de recursos financeiros, materiais e humanos para novos projetos e a crescente mobilidade (viagens técnicas, assessorias a outros órgãos, participaçōes em congressos) permitida pela Empresa. Finalmente, apesar de a Empresa se apropriar do produto de seu trabalho, o pesquisador, na Embrapa, não tem seu nome desvinculado desse. Além disso, ele tem a difusão do conhecimento por ele gerado garantida institucionalmente (modelo "república da ciência"). Verifica-se, portanto, que a Embrapa, apesar de poder ser denominada uma tecnoburocracia, reúne muitas características dos outros tipos de organizações de pesquisa, principalmente as do modelo de "progresso técnico".

Segundo Marcovitch (1980), as instituições de pesquisa necessitam de dois perfis organizacionais: um subsistema de "apoio" e um de "projetos". Também na Embrapa podem ser claramente identificados e diferenciados estes dois perfis. Ambos serão caracterizados a seguir.

No subsistema de "apoio" predominam as atividades de rotina. Sua estrutura é mais centralizada. Os procedimentos são formalizados. Os niveis hierárquicos são mais estratificados ou verticais. A comunicação é periódica e impessoal. No caso da Embrapa, o perfil de "apoio" predomina na administração central, particularmente naqueles departamentos encarregados de administrar a informação, o patrimônio, os materiais, os recursos financeiros e o processo de controle e desenvolvimento dos recursos humanos.
O perfil de "apoio" também se reflete em parte da estrutura das unidades de pesquisa da Empresa, particularmente nas operaçōes administrativas executadas em consonância ou coordenadas pela administração central. Neste subsistema encontram-se, em maior número, os papéis ocupacionais da carreira de administração geral almoxarifes, auxiliares e assistentes administrativos, secretárias, assistentes executivos, auditores, operadores e programadores de computador e analistas de sistema.

Ao contrário do subsistema de "apoio", que faz a administração para a pesquisa, o subsistema "projetos" realiza a administração da pesquisa. Nele, as decisões são mais descentralizadas. Os procedimentos são menos formalizados. A comunicação é intensa e pessoal. As estruturas hierárquicas são menos verticais e têm definiçōes de atribuições menos precisas. Há, por parte da instituição, um grande esforço no sentido de descentralizar a execução da pesquisa, de exercer uma política de planejamento participativo no que concerne à formulação das diretrizes gerais dos programas e projetos, de estimular a autonomia dos pesquisadores e de valorizar projetos audaciosos de pesquisa (Alves e Pastore, 1980). É neste subsistema que se localiza o objeto de estudo do presente trabalho: seus gerentes.

O subsistema de "projetos" é mais visível nas unidades de pesquisa da Embrapa. É principalmente nelas que se planejam, coordenam, executam, avaliam e difundem pesquisas. Neste subsistema encontram-se, em maior número, os papéis ocupacionais das carreiras de apoio à pesquisa (pessoal de campo, técnicos agrícolas, pessoal de laboratório, operadores de máquinas e veículos, pessoal de biblioteca, de desenho e dẹ impressão) e técnicocientífica (pesquisadores graduados e, na maior parte, pós-graduados, com especializações nas diversas áreas da agronomia, veterinária, estatística e matemática e das ciências biológicas, químicas, econômicas e sociais).

Apesar de menos presente do que nas unidades de pesquisa, o perfil de "projetos" também existe na administração central da Empresa. Nesta, ele é visível naqueles setores e níveis hierárquicos encarregados de: a) negociar e definir políticas e diretrizes da pesquisa agropecuária; b) relacionar-se com o meio ambiente político; c) acompanhar e avaliar o desenvolvimento de programas de pesquisa; d) coordenar e executar macroavaliaçōes e estudos sobre o processo de administração e os efeitos da pesquisa agropecuária; e) decidir sobre a política e $o$ desenvolvimento de recursos humanos para a pesquisa e sobre as coordenadas do processo de difusão dos conhecimentos e tecnologias desenvolvidos pela Empresa.

Os dois subsistemas ou perfis presentes nas instituições de pesquisa necessitam de estruturas e climas organizacionais bem diferenciados. Por isso, exigem gerentes possuidores de papéis organizacionais bem distintos, quando não conflitantes. Fundamentalmente, cabe ao gerente de "apoio" o controle de processo e, portanto, o papel de mantenedor das regras e normas de procedimentos estabelecidas. Esta característica, caso seja dominante no gerente do subsistema de "projetos", pode resultar na completa destruição do clima necessário à produção científica e, portanto, na derrocada da instituição de pesquisa. 
A fim de que se possa compreender melhor o papel deste último tipo de gerente, serão descritas a seguir algumas condições presentes e/ou necessárias à manutenção ou criação de uma estrutura e de um clima organizacionais favoráveis à criatividade científica ou, tal como definiu Pereira (1980), ao processo de resolução de problemas científicos.

\section{MODELO ORGANIZACIONAL E CRIATIVIDADE CIENTIFICA}

A organização da Embrapa, no que se refere às suas atividades-fim (perfil de "projetos"), tem similaridades com o modelo orgânico de instituições de pesquisa proposto por Burns e Stalker (1961). Sua estrutura de poder, sendo descentralizada, permite aos pesquisadores participação em muitas tomadas de decisão. Isso provoca uma difusão de influência que, segundo Pelz e Andrews (1976), contribui para aumentar a produção científica. Estes autores verificaram que são as estruturas hierárquicas mais "achatadas", que permitem mais contatos e mais decisões em equipe, que determinam um clima mais propício à criatividade. Ao contrário, foi nas instituiçōes de pesquisa com estruturas organizacionais muito verticais que eles encontraram pouca produtividade científica.

Este modelo orgânico, argumenta Hage (1982), torna os indivíduos mais visíveis e, portanto, o controle do seu comportamento é mais exercido por pressão do grupo técnico ou equipe interdisciplinar do que pelos gerentes. Assim, se os gerentes de pesquisa desejam exercer plenamente sua autoridade, ela deve resultar mais de sua competência técnico-científica do que do poder a eles concedido pela instituição. Por outro lado, o gerente pode utilizar, a um nível "micro", a capacidade de controle exercida pela equipe (aprovação social) como um meio de recompensar e motivar o pesquisador. Ao nivel "meso", ainda lhe resta a possibilidade de utilizár do poder burocrático-organizacional, já discutido anteriormente, de que dispõem as tecnoburocracias para poderem recompensar os pesquisadores mais produtivos.

Poderia ser questionado que o aumento do controle sobre o comportamento do cientista reduziria sua autonomia e, conseqüentemente, sua criatividade. Contudo, a literatura sobre o assunto descreve resultados de pesquisa que não apontam para esta direção. Pelz e Andrews (1976) relatam, em suas investigaçőes, que a mais alta produtividade científica está sistematicamente relacionada à presença de um nível de coordenação exercida sobre os pesquisadores. Parece que alguma quantidade de coordenação, principalmente se exercida por alguém tido como técnica ou cientificamente competente, aumenta no pesquisador a percepção do desafio que lhe impõe a tarefa. Este desafio, como foi demonstrado por Pelz e Andrews, aumenta a produtividade.

Outro aspecto do problema da relação entre autonomia e criatividade ocorre ao nivel do controle que o grupo exerce sobre cada pesquisador. Outra vez, Pelz e Andrews encontraram que a influência exercida por colegas, clientes e até subordinados aumenta a produção científica. Os resultados de sua extensa investigação também indicam que o criticismo exercido pelo grupo pode manter alta a produção do pesquisador, motivan- do-o para o trabalho e aumentando a relevância da tarefa que ele executa. Significativamente, os melhores desempenhos são encontrados em cientistas que mantém uma grande quantidade de interaçōes com colegas.

Além da influência positiva que a estrutura descentralizada de poder, a autoridade exercida a um nivel técnico e o sistema de recompensas sociais do grupo podem exercer sobre o indivíduo nas estruturas orgânicas, a comunicação horizontal e com o ambiente e o trabalho em equipes interdisciplinares, compostas de uma variedade de especialistas, são outras características importantes deste tipo de modelo de instituição de pesquisa. Estes outros fatores serão discutidos a seguir.

A comunicação horizontal é importante como um instrumento facilitador de dialética (Hage, 1982). Assim, ela possibilita que as idéias dos pesquisadores passem pelo processo de tese, antítese e síntese ou, como descrevem Pereira (1980) e Quirino, Pereira e Borges-Andrade (1980), pelo processo de sucessivos desequilibrios e equilibrações cognitivos que ocorre com o indivíduo criativo. Este processo psicológico parece ser condição essencial à produção científica. As evidências sócio-organizacionais acumuladas por Pelz e Andrews (1976) são coerentes com esta linha de argumentação. Eles relatam que a conjugação de harmonia pessoal e conflito intelectual entre cientistas aumenta a criatividade. Relatam também que aqueles que conversam com pessoas que têm perspectivas diferentes das suas, e que portanto se expõem mais à crítica e ao desequilíbrio cognitivo, têm uma probabilidade maior de serem criativos.

Outra razão, que justifica a importância da comunicação horizontal, é a de que ela leva à chamada solução de grupo: "Pode haver um indivíduo em particular que é mais criativo e sugere mais idéias, mas então estas idéias são apanhadas e trabalhadas por outros membros. Esta transformação gradual de idéias no tempo leva a uma solução de grupo que é muito melhor" (Hage, 1982). Parece que o que descreve este autor é uma espécie de processo de sucessivos desequilíbrios e equilibrações cognitivos, que também ocorreria ao nível do grupo. Ou, em outras palavras, seria a equipe funcionando como unidade ou "indivíduo" criativo.

Há outro sentido da comunicação que, segundo Hage (1982), é importante no contexto das estruturas orgânicas de instituições de pesquisa. Ele refere-se à troca de informações que o cientista deve manter com o seu ambiente. $\mathrm{O}$ modelo de organização de pesquisa da Embrapa propõe que o pesquisador deva manter-se em interação dialética com o ambiente da produção agropecuária (ver Alves, 1980a). Esta interação deve estar presente desde o momento em que o indivíduo escolhe e define o problema sócio-técnico a ser investigado até aquele em que ele deve prover condições e planejar estratégias para a difusão dos conhecimentos e tecnologias gerados (ver Alves, 1980b; e Quirino, 1981).

Um outro tipo de comunicação com o ambiente refere-se ainda àquele que o pesquisador realiza com colegas e outras instituiçóes, já que o conhecimento e as tecnologias, por seu caráter mutável, obrigam-no a buscar meios pelos quais possa se aperfeiçoar e atualizar. Estes meios são geralmente os encontros, congressos e viagens técnicas. Na Embrapa, por exemplo, o Programa de Capacitação Contínua (Coqueiro, 1981) atende a esta ne- 
cessidade. Também no que se refere ao aspecto da comunicação com o ambiente das instituições de pesquisa, Pels e Andrews (1976) oferecem fundamentação empirica relevante. Eles relatam, por exemplo, que as estimulações internas e externas produzem cientistas mais efetivos.

O sexto elemento a ser considerado em instituições de pesquisa, como a Embrapa, refere-se às equipes interdisciplinares compostas de uma variedade de especialistas. Há várias razões para considerá-las como determinantes relevantes de um clima organizacional favorável à produção científica.

O fato de a Embrapa ter como objetivo o desenvolvimento de pesquisas para resolver problemas da agricultura brasileira caracteriza a ciência a ser produzida como finalista. Esta ciência é, quase sempre, impossível de ser definida dentro dos limites de uma área de conhecimento. Em outras palavras, a prioridade é dada à resolução de problemas práticos, que geralmente têm ramificações por mais de uma disciplina científica, e não à resolução de problemas teóricos, usualmente restritos a uma ou duas áreas de conhecimento. A diferença que se deseja fazer aqui é entre a pesquisa tradicional feita nas universidades e aquela definida para uma organização como a Embrapa. Ou, respectivamente, entre os modelos de pesquisa “difuso" e "concentrado" (Alves, 1980c).

$\mathrm{O}$ modelo concentrado, sendo finalista, inicialmente demanda qualidade dos recursos humanos (Quirino, Borges-Andrade e Pereira, 1980). Suponha-se que tenha ocorrido, por parte da instituição, um esforço no sentido de especializar seus pesquisadores. Então, o modelo passa a obrigar os gerentes de pesquisas a formarem equipes interdisciplinares, que abriguem e controlem este pessoal agora altamente qualificado e diversificado. Isto é, ele passa a exigir, para seu efetivo funcionamento, a aplicação coordenada de "(...) saberes originários de diferentes disciplinas (...)" no estudo dos problemas a serem pesquisados, "(...) de forma que o produto final seja distintamente unitário" (Quirino, 1981). Caso a instituição falhe em constituir estas equipes interdisciplinares, este seu produto, que é a pesquisa aplicada, dificilmente é alcançado. Agora, além de importar o fato de que ela conte com um pessoal bem qualificado, passa a importar também que este pessoal esteja integrado em equipes interdisciplinares.

Havendo falha na formação das equipes interdisciplinares, os administradores de pesquisa pouco experientes acabam por constituir, em contraposição, as equipes multidisciplinares. Nelas, geralmente prepondera "(...) a consideração de um objeto de estudo sob o ângulo de diferentes disciplinas do saber, sem necessariamente haver entrosamento entre estas" (Quirino, 1981). O resultado final é a departamentalização dos programas de pesquisa por área de conhecimento, em que a existência de objetivos comuns é mera formalidade. Nestes programas, o que realmente passa a ocorrer é a divisão dos recursos existentes entre projetos, geridos por pequenas equipes unidisciplinares, que definem e só resolvem problemas de pesquisa limitados à sua área de especialização: Retorna-se assim ao modelo difuso de pesquisa, que é pouco eficaz no tratamento de problemas de ciência aplicada e pode ter uma relação custo-benefício desfavorável (Pastore e Alves, 1980). Os seus efeitos passam a ser devas- tadores para uma instituição que recebe dinheiro público e que não consegue cumprir sua missão social.

Os centros de pesquisa mais antigos e algumas instituições, como as universidades, em que prepondera 0 modelo difuso, têm tentado transformar (Lo Ré, 1980) suas organizaçōes de linhas funcionais (ou departamentalizadas) em organizações por projeto (modelo concentrado). Isso implica em transformar estruturas verticais em horizontais e em integrar várias disciplinas sob uma coordenação. Estas mudanças, de acordo com Lo Ré, determinam a formação de gerentes diferentes, altamente qualificados e experientes. Pelo menos dois tipos de estruturas organizacionais podem resultar das mudanças em direção a um modelo concentrado: estruturas por projetos e matriciais.

As estruturas por projetos são mais adequadas para a pesquisa aplicada, com atividades muito complexas e com objetivos bem definidos a serem atingidos a curto prazo. Elas obrigam os especialistas a uma maior subordinação aos problemas de pesquisa do que às suas disciplinas de formação.

As estruturas matriciais, por outro lado, não eliminam completamente o conceito de trabalho por área de especialização, mas representam a superposição (Vasconcellos, 1980) deste com o de trabalho por projeto. Cabe aos gerentes destas estruturas o papel de coordenação para se investigar os problemas propostos. Também cabe a eles o de administrar o conflito que certamente surge entre as perspectivas da linha de apoio e da linha de projetos.

E interessante notar que exemplos de estruturas por projetos e de estruturas matriciais podem ser encontrados na Embrapa e que estes dois tipos parecem fazer parte de um único continuum. Nos dois casos, o que essencialmente deve preponderar, para a sobrevivência da instituição de pesquisa, é o conceito de equipe interdisciplinar.

Pelz e Andrews (1976) apresentam resultados de investigação que indicam que, até um determinado limite, o contato do pesquisador com outros que tenham perspectivas (orientações teóricas) diferentes das suas próprias e a diversidade de atividades aumentam a criatividade científica. Por um lado, a interpretação destas evidências parece ser a de que estes contatos e esta diversidade aumentam o espectro cognitivo de elementos, do qual o indivíduo possa obter soluções engenhosas. De outro, de acordo com Hage (1982), quando a organização de pesquisa “(...) põe juntas perspectivas diversas relevantes para alguma tarefa comum de pesquisa, então há uma base estrutural para a dialética intelectual". Assim, essas parecem constituir um importante conjunto de justificativas para a formação e manutenção, em instituições de pesquisa com estruturas orgânicas, de equipes interdisciplinares com uma diversidade de especialistas.

\section{CARACTERISTICAS DO PAPEL DE ADMINISTRADOR DA PESQUISA}

O papel ocupacional que cabe ao administrador da pesquisa tem características próprias, determinadas em função do fato de que ele atua no subsistema denominado de "projetos", como já foi descrito no item 2 do presen- 
te trabalho. Portanto, a identificação destas características permite definir o papel do gerente nestas instituições. Esta definição de papéis tem implicações teóricas, metodológicas e práticas a serem discutidas a seguir, que a tornam muito importante para o processo de se planejar o desenvolvimento dos referidos administradores de pesquisa.

O conceito de papéis adquiriu importância na literatura, na medida em que ele estabelece laços entre a psicologia e a sociologia (ver Dahrendorf 1969; e Katz e Kahn, 1978). Ele o faz oferecendo proposições para analisar simultaneamente a organização, ou algum de seus segmentos, em termos dos indivíduos que dela fazem parte, das relações existentes entre eles e do comportamento dos grupos sociais que eles constituem. Portanto, a definição dos papéis ocupacionais dos gerentes de pesquisa fornece um quadro referencial teórico para seu estudo.

Uma segunda implicação, de natureza metodológica, decorre da teórica. A avaliação de necessidades de treinamento exige, como propõem Borges-Andrade e Lima (1982), que se levantem e se identifiquem as tarefas ou habilidades que caracterizam o papel ocupacional da população potencial de treinandos. É a partir delas que se procede à avaliação de necessidades propriamente dita. Assim, se é importante implementar a formação de administradores da pesquisa e, para isto, é necessário avaliar necessidades, deve-se inicialmente empreender esforços no sentido de definir o papel ocupacional destes individuos.

O levantamento destas habilidades tem outras importantes utilidades. Ele pode servir para estabelecer parâmetros para os processos de seleção e de avaliação de desempenho dos administradores da pesquisa. Além disto, a caracterização do papel destes administradores tem como consequeência o reconhecimento e a legitimação, a nivel da instituição, das tarefas que ela espera que sejam desenvolvidas pelos seus administradores. Desta forma, fica um pouco mais fácil para estes indivíduos compreenderem suas responsabilidades e agirem no sentido de cumpri-las e de atingir os objetivos organizacionais.

A seguir, serão apresentadas algumas sugestões de indicadores e características do papel do gerente em instituições de pesquisa. Para fazê-lo, decidiu usar três fontes de informaçốes: as características do clima organizacional ideal no qual o indivíduo deverá atuar, a literatura existente sobre o papel do administrador de pesquisa e a análise do cargo de pesquisador que acaba de ser realizada na Embrapa (Borges-Ândrade e outros, 1980).

Em item anterior discutiu-se, conforme o que encontraram os pesquisadores da área, as características essenciais de um clima organizacional favorável à criatividade científica. É responsabilidade do administrador da pesquisa a manutenção e criação deste clima. Aquelas características, portanto, podem fornecer vários indicadores sobre a direção e o sentido que devem ter as atitudes deste indivíduo, bem como apontam as ênfases que podem ser dadas ao seu treinamento. Assim, é de extrema importância ter em perspectiva aqueles seis conjuntos de fatores determinantes de uma efetiva produção científica: estrutura descentralizada de poder, exercício da autoridade a um nível técnico, sistema de recompensas sociais, comunicação horizontal e com o ambiente e trabatho organizado em equipes interdisciplinares.
Vaz (1981) defende o ponto de vista de que o responsável pela administração da pesquisa deve ser um pesquisador experimentado. Este pesquisador, para exercer liderança, deve ser capaz de compreender seus comandados e suas tarefas, bem como o próprio processo de construção do conhecimento. Como conseqüência, ele terá mais chances de exercer o controle pela competência técnica e pela correta manipulação do sistema de recompensas sociais e do poder burocrático-organizacional. Ele estará também mais capacitado a administrar os conflitos que inevitavelmente surgem (Lo Ré, 1980) entre as linhas de apoio e de projetos e/ou entre os dois perfis organizacionais, já que é provavelmente visto pelos cientistas como um deles. A este respeito, tem sido demonstrado que modelos humanos percebidos pelos sujeitos como seus semelhantes sociais e como competentes têm probabilidades bem mais elevadas de exercer controle social (Borges-Andrade, 1981). Também Lo Ré (1980) aponta a alta qualificação profissional como condição necessária ao gerente de projetos.

A discussão sobre se a administração da pesquisa deve caber a pesquisadores ou a técnicos especializados em administração é similar àquela, há muito existente entre médicos e estes profissionais, sobre a administração de hospitais. A presença dos primeiros ocupando papéis gerenciais traz as vantagens mencionadas, mas deve ser acompanhada de um esforço institucional para treinálos em administração. Os segundos, embora detenham a seu favor toda uma formação profissional, carecem da compreensão do processo pelo qual a atividade-fin (pesquisa) é realizada.

Ao que tudo indica, esta compreensão pode requerer mais tempo do que aquele necessário à implementação de programas de treinamento em administração para os pesquisadores. Assim, a opção por técnicos especializados em administração parece apresentar uma relação custo-benefício mais desfavorável. Deve ser lembrado, contudo, que se está aqui fazendo referência àquelas atividades gerenciais inerentes ao subsistema "fim". 0 outro subsistema presente nas instituições de pesquisa, 0 de "apoio", deve permanecer ocupado por pessoal especializado nos diversos campos da administração aplicada (administração, economia, contabilidade, direito, psicologia e sociologia). A maioria das instituições de pesquisa, incluindo a Embrapa, tem optado por esse tipo de solução.

Além da experiência na execução de pesquisas, outra característica que parece essencial ao papel do gerente é de natureza afetiva. Ela se refere ao fato de que os indivíduos que ocupem este cargo valorizem, em alto grau, a inovação e a criatividade. Segundo Hage (1982), este traço de personalidade, independentemente das variáveis de clima organizacional mencionadas em item anterior, pode tornar elevados os índices de produção científica. Continuando, Hage afirma que, de acordo com a investigação realizada por ele e Dewar (1973), o que parece importante e fundamental é que o administrador se apresente "aberto para mudar" ou que "valorize a mudança", independentemente de por si só ter preferência por inovações.

Este traço de personalidade, que pode ser usado como parâmetro nos processos de seleção e de planeja- 
mento de treinamentos, é parte integrante de outra importante característica dos gerentes de pesquisa. É a capacidade de realizar planejamento estratégico, citada por Hage (1982), isto é, a de observar as mudanças tecnológicas e políticas em andamento no meio ambiente da instituição de pesquisa e de, com base nelas, predizer onde estará a organização, a sociedade e o conhecimento nos próximos cinco ou 10 anos. Em seguida, fundamentado nelas e na adequada compreensão das metas da instituição, ser capaz de elaborar e revisar continuamente o planejamento de pesquisa. Ainda segundo este autor, é estimulante para o administrador ter um plano estratégico para os seus projetos de pesquisa e relacioná-los à missão social da sua instituição.

Do ponto de vista instrucional, a capacidade de realizar planejamento estratégico está relacionada à aprendizagem de três habilidades bem diferentes. Uma, de natureza intelectual, refere-se à tarefa de definir objetivos, estabelecer sua seqüência de atendimento, descrever seus indicadores de alcance, decidir sobre as estratégias exigidas para atingi-los e implementá-las, determinar os prazos, avaliar a efetividade do sistema e revisá-lo quando necessário. Trata-se, genericamente, da habilidade de planejar, que Lo Ré (1980), ao prescrever para o gerente de pesquisa, subdivide em planejamento, execução, controle e avaliação. Outra habilidade é uma atitude. Ela diz respeito à capacidade de aceitar mudanças sociais, já discutidas anteriormente. A terceira é a de interpretar estas mudanças. Estas habilidades devem, portanto, ser adquiridas pelos responsáveis pela administração da pesquisa.

$E$ interessante observar como algumas características do administrador de pesquisa discutidas por Marcovitch (1980), embora estreitamente relacionadas às recomendações de Hage (1982), ampliam as deste. Argumenta-se, assim que é papel deste indivíduo realizar o continuo planejamento estratégico, a fim de que, nos diversos níveis hierárquicos, as metas da instituição (obtenção de conhecimentos e tecnologias) estejam sempre presentes e claras, tornando a maioria das atividades e dos empregados voltados para aquelas metas.

Esta habilidade exigiria do gerente uma constante preocupação com os fins da sua instituição e dos seus programas e projetos, bem como o seu futuro. Ele também seria pressionado, pelo menos nos níveis hierárquicos mais elevados, a identificar os sistemas externos que influenciariam sua organização e que dela receberiam influência. Finalmente, pelo menos nestes niveis, ele determinaria as próprias metas da organização e a direção a ser por ela seguida.

A administração participativa, de acordo com Lo Ré (1980), é uma característica do gerente de projetos e programas de pesquisa. Assim, considerando que os participantes da equipe detêm um alto nível de qualificação, o gerente deveria estimulá-los a participarem das decisões. A prescrição de Lo Ré é coerente com as conclusões sobre estrutura descentralizada de poder feitas em item anterior.

Outras características indicadas por Lo Ré são a existência, no indivíduo, de uma visão global sobre o meio ambiente e um conhecimento diversificado e atualizado sobre a tecnologia e o conhecimento científico objetos da pesquisa que administra. Também estas indicações estão em consonância com a discussão anterior sobre clima organizacional, particularmente no que se refere à autoridade técnica do gerente, ao processo dialético (comunicação horizontal), à comunicação com $o$ ambiente e ao trabalho em equipes interdisciplinares.

Há ainda uma série de preocupaçð̃es e interesses que, segundo Marcovitch (1980), fariam parte do papel do administrador de pesquisa. Ressalta-se, por exemplo, que seria sua a preocupação com a estrutura normativa da organização. Isto resultaria da sua freqüente participação em trabalhos de delineamento, adaptação e implantação de estruturas na instituição.

Da mesma maneira, o gerente se sentiria interessado na solução de problemas de alocação de recursos materiais e humanos. Estes últimos, sendo o mais importante "equipamento" disponivel para a produção científica, teriam, no que concerne ao seu desenvolvimento, uma especial atenção por parte dele. Assim, seria de responsabilidade sua "pensar" as políticas salariais de treinamento e de avaliação de desempenho, por exemplo, bem como identificar necessidades de treinamento dos pesquisadores sob seu comando. Essas habilidades, dependendo do nível de responsabilidade que lhe seria atribuída pela instituição, poderiam significar a necessidade de: a) somente adquirir informações gerais sobre administração, b) modificar atitudes administrativas; ou de c) até mesmo ter de aprender conceitos, princípios e métodos de resolver problemas técnicos de administração. Assim, o próprio grau de especialização em administração pode variar, em função do nivel de responsabilidade de cada gerente.

Essas habilidades, que envolvem o trato de questões jurídico-institucionais e de recursos materiais e humanos, não estão diretamente relacionadas com o conteúdo das variáveis de clima organizacional já mencionadas. Contudo, elas parecem fazer parte do repertório do gerente, principalmente daquele presente nos mais elevados niveis hierárquicos da instituição. A razão para isto parece estar no fato de que elas tratam com eventos que são pilares de sustentação da organização e, portanto, garantia de segurança e sobrevivência para 0 - individuo que nela exerce seu poder e dela depende para continuar exercendo-o.

Marcovitch (1980) ainda menciona duas outras tarefas do gerente. Uma delas é a de tornar mais eficaz a troca de informações entre a instituição de pesquisa $\mathrm{e}$ sua clientela, a fim de identificar demandas. $\mathrm{Na} \mathrm{Em}$ brapa, em que a clientela é o produtor rural, poderia significar, por exemplo, lançar mão de agentes extensionistas e ex-extensionistas que, na Empresa, comporiam. equipes interdisciplinares. Esta tarefa parece estar relacionada com um dos aspectos do clima organizacional de instituições de pesquisa, que é o da comunicação com o ambiente.

A outra tarefa citada por Marcovitch parece também ser típica dos gerentes de níveis hierárquicos mais altos. É a de tornar mais eficaz a troca de informaçōes e de aumentar $o$ poder de barganha que pode ser utilizado pela organização. Ela teria como objetivo auscultar e exercer influência sobre órgãos que afetem o meio ambiente da organização de pesquisa e, assim, obter suporte político-institucional. Ela poderia se mostrar, por exemplo, na implantação de uma política que sistematicamente permitisse ceder temporariamente pessoal qualificado 
para (e contratar indivíduos oriundos de) certos órgãos públicos. Neste caso, o objetivo desta política poderia ser o de influenciar a adoção de tecnologias geradas pela pesquisa, estabelecer linhas de crédito para o financiamento destas tecnologias, obter conhecimentos e tecnologias fora da organização ou determinar setores e áreas em que se devesse desenvolver pesquisas.

Nos momentos em que se mencionou aqui as tarefas de planejamento, houve a deliberada omissão das habilidades concernentes à programação orçamentária. De acordo com Quinn, "desde a metade dos anos 50, o conceito de programação orçamentária para a pesquisa foi tão amplamente aceito que quase todas as grandes instituições que patrocinam pesquisas... adotaram um sistema de programação orçamentária para ajudá-las no planejamento de atividades de $P$ \& D". Assim como o planejamento, a programação orçamentária exige a habilidade de análise, para que se possa definir programas e projetos em termos de seus elementos.

Em muitas organizações de pesquisa, a aplicação dos princípios técnicos envolvidos na programação orçamentária é papel ocupacional dos indivíduos pertencentes ao perfil de "apoio". Noutras, ele é característico do gerente do perfil de "projetos". Contudo, pelo menos as responsabilidades por: a) garantir que determinado orçamento represente as necessidades da instituição; b) ter conhecimento dos quantitativos disponíveis em cada elemento de despesa; c) supervisionar a distribuição de fundos e suas eventuais revisões, são sempre do administrador da pesquisa. Elas são geralmente atividades detestadas por ele. Entretanto, elas podem, conforme Quinn, resultar em alguns benefícios indiretos para ele, ao forçá-lo a avaliar periodicamente o andamento dos programas e projetos de pesquisa e a revisá-los quando necessário.

As características do papel do gerente de pesquisa foram tratadas, no presente trabalho, de forma seqüencial. Não existiu, até agora, a preocupação de categorizar ou hierarquizar papéis. Ê chegado o momento de fazê-lo, no que concerne à Embrapa.

\section{PAPÉIS DE ADMINISTRAÇÃO DA PESQUISA NA EMBRAPA}

$\mathrm{Na}$ Embrapa podem ser reconhecidos pelo menos três níveis de administradores da pesquisa. No escalão mais elevado estão os diretores, os chefes de assessorias e departamentos que têm atividades relacionadas ao perfil organizacional de "projetos" e os chefes de centros e unidades de pesquisa. No nivel intermediário estão os chefes adjuntos, os subchefes e os coordenadores de programas nacionais de pesquisa. No nível básico estão os responsáveis por projetos de pesquisa, por equipes de pesquisadores e por laboratórios ou campos experimentais. Em alguns casos, principalmente nos níveis intermediário e básico, pode existir um mesmo indivíduo atuando simultaneamente em papéis pertencentes a dois escalōes.

O papel de nível básico e o de coordenação de programas nacionais não estão definidos como cargos comissionados, isto é, não fazem jus a remuneração especial resultante do seu exercício. Além disto, eles geralmente não ocupam todo o tempo disponivel dos individuos que neles atuam. De acordo com as normas institucio- nais e com os valores da cultura organizacional vigente, estes indivíduos ainda são considerados pesquisadores.

Poderia ser argumentado que esta política seria inadequada, já que ela colocaria, lado a lado, pesquisadores de tempo integral com pesquisadores que exercem outras atividades. E que, por isto, estes últimos levariam desvantagem ao terem sua produção científica avaliada. A referida política não é, contudo, inconsistente com os resultados dos estudos de Pelz e Andrews (1979) e com o quadro teórico construído por Hage (1982). Existem muitas evidências empíricas de que aqueles indivíduos que combinam atividades de pesquisa com outras, como ensino ou administração, têm maior criatividade cientí. fica do que os que se dedicam exclusivamente àquelas. Há inclusive resultados que indicam que a proporção ideal é de 70 a $80 \%$ para as primeiras e de 30 a $20 \%$ para as do segundo tipo, conforme estes mesmos autores.

A Embrapa ainda não desenvolveu investigações no sentido de levantar e definir as características dos papéis ocupacionais de seus gerentes, bem como de categorizá-los em função das evidências encontradas. No entanto, uma metodologia aplicável já foi utilizada e resultou num conjunto de informações que deve ser aqui apresentado.

Em 1980, o Departamento de Recursos Humanos (DRH) da Embrapa decidiu empreender esforços no sentido de gerar conhecimentos para subsidiar uma mudança no Plano de Cargos e Salários (PCS) da Empresa. Um dos subprojetos de pesquisa, então desenvolvidos, tinha como meta '“(...) analisar, em termos de seus nivveis de habilitação e de suas prescrições comportamentais e habilidades, os cargos... em vigor na Embrapa (...)" (Borges-Andrade e outros, 1980). Os dados referentes a este subprojeto foram colhidos junto a uma amostra representativa de aproximadamente $15 \%$ (mais de mil) dos empregados, no primeiro semestre de 1981. Estes dados foram, em seguida, analisados.

Um dos resultados obtidos com o subprojeto foi a descrição dos cargos de pesquisador, da carreira técnico-científica, em termos de 13 diferentes funções (segundo Quirino e Pereira, 1980, "função é uma parte ou total do comportamento previsto para um cargo"). Uma destas funções congrega as prescrições comportamentais típicas de administração de pesquisa, realizadas por pesquisadores de nível I, II e III, portadores respectivamente de títulos de B.Sc., M.Sc. e Ph.D. Estes resultados são apresentados na tabela 1 .

Deve ser resssalvado que as prescrições da tabela 1 não descrevem os papéis ocupacionais de todos os três escalões de gerentes da Empresa. Elas só podem ser consideradas representativas das tarefas realizadas pelos gerentes do nível básico e pelos coordenadores de programas nacionais de pesquisa (nível intermediário). Esta limitação se deve ao fato de que o subprojeto de pesquisa, levado a cabo pelo DRH, limitou seu universo ao dos ocupantes de cargos de provimento efetivo (pertencentes a cargos de carreiras) na Empresa. Assim, ele eliminou do estudo todos aqueles pesquisadores que simultaneamente estivessem ocupando cargos em comissão.

Maximiano (1980) sugere uma categorização das habilidades gerais dos administradores de pesquisa em três grupos: habilidades técnicas, habilidades de relaciona- 
Tabela 1

Descrição das tarefas de administração da pesquisa realizadas pelos pesquisadores na Embrapa

\section{Pesquisador I}

Pesquisador II

1. Estuda, propõe e avalia novos métodos de administração de pesquisa.

2. Coordena avaliações técnico institucionais (ex.: de unidades e órgãos do SCPA)

3. Acompanha o desenvolvimento da estrutura administrativa da organização.

4. Analisa as características da empresa e determina a metodologia a ser usada nos serviços ligados à análise, classificação e avaliação de cargos.

5. Faz administração de pessoal (ex.: treina, seleciona e distribui tarefas; orienta estagiários e técnicos: faz assessoramento a técnicos c pós graduando determina procedimentos)

6. Administra material de pesquisa (ex, : controla entrada e saída, controla o material existente, projeta e controla a fabricação de material).

7. Efetua a administração $e$ manutençâo de arquivos

8. Administra atividades financeiras relacionadas à pesquisa.

9. Coordena e administra laboratórios.

10. Orienta e supervisiona traballios de cainpo.

11. Promove a seguranca do ambiente de trabalho (ex: orienta sobre a prevencão de acídentes no campo e nos laboratórios).

12. Elabora, coordena e avalia projetos de pesquisa (cx.: cria métodos de planejamento $\mathrm{e}$ avaliação, planeja metodologias, participa de comissões especificas).

13. Planeja equipamentos para a montagem de linhas de produção.

14. Promove e participa de atividades de integração das unidades da empresa e desta com outros órgãos (ex.: reuniões, discussões de relatórios, demonstrações)

15. Atende a consultas e emite parecerestécnicos (ex.: laudos)
Pesquisador III

1. Faz estudos pertínentes a recrutamento, seleção, treinamento e promoção de pessoal.

2. Analisa as características đa empresa e determina a metodologia a ser usada nos serviços ligados à análise, elassificicação e avaliação de cargos.

3. Realiza estudos sobre providencias administrativas a serem tomadas.

4. Estuda e propóe métodos rotina de simplificação e racionalização dos serviços e respectivos planos de aplicação.

5. Estuda, propóe e analisa a implantação de novos métodos de trabalho.

6. Coordena programas de pesquisá.

7. Coordena, organiza, orienta e supervisiona os trabalhos de laboratórios.

8. Faz administração de pessoa (ex.: programa e desenvolve o treinamento e a seleção; orienta bolsistas, técnicos, pesquisadores $e$ alunos de mestrado).

9. Promove o conforto e a segurança dos ambientes de trabalho.

10. Faz administração c controle de material.

11. Acompanha o desenvolvimento da estrutura administrativa da organização

12. Participa de reuniốes e comissōes para discutir e resolver problemas da empresa e de outras instituições

13. Assessora e dá consultorias a órgãos governamentais, a unidades de pesquisa e a diretoria da empresa.

14. Redige laudos $\mathrm{s}$ pareceres técnicos.

15. Redige correspondências atendendo a solicitações diversas. mento pessoal e habilidades estratégicas, metodológicas ou conceituais. Além disto, ele relata que cada uma destas categorias predominaria em diferentes niveis hierárquicos, embora não fosse exclusiva de nenhum deles. Sua proposta é interessante e torna-se tentador relacioná-la aos níveis hierárquicos da Embrapa mencionados anteriormente. A figura 1 representa estas possíveis relações.

Observa-se, na figura 1 , que os papéis ocupacionais de nível mais elevado só requeririam habilidades estratégicas, metodológicas ou conceituais e de relaciona- mento pessoal. Nenlıuma habilidade técnica seria exigida deste tipo de gerente, já que tarefas que delas necessitam seriam delegadas aos outros níveis de administração.

No escalão intermediário predominariam as habilidades de relacionamento pessoal, embora fossem também necessárias, em menor quantidade, as das outras duas categorias. Finalmente, no nivel básico, as habilidades técnicas seriam maioria, seguidas somente das de relacionamento pessoal. 
Figura 1

Relaçбes existentes entre as habilidades gerais dos administradores de pesquisa e seus níveis hierárquicos na

Embrapa, conforme a proposta original de Maximiano (1980)

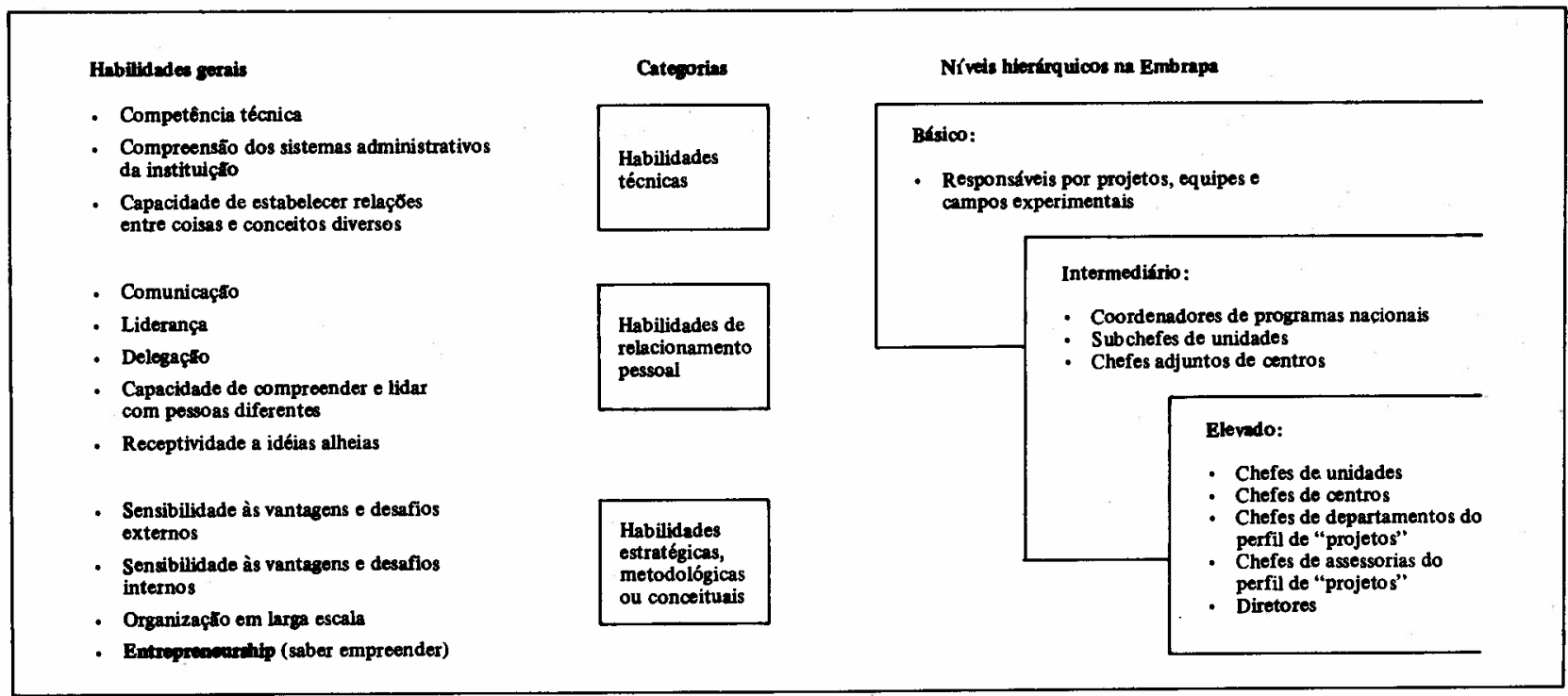

\section{CONCLUSÃO}

Encerra-se o presente trabalho com a certeza de que a investigação sobre clima organizacional e produção científica, a análise organizacional de instituições de pesquisa, a literatura sobre papéis ocupacionais e os resultados das investigações sobre cargos em instituições de pesquisa podem oferecer muitos subsídios para o estudo dos papéis gerenciais na administração da pesquisa. Mas conclui-se que estas fontes, embora ricas em informações, não substituem a pesquisa que deve ser feita a fim de legitimar, a nivel de cada instituição de pesquisa, os papéis que venham a ser definidos para seus gerentes. Isso é um pré-requisito indispensável para a seleção eficaz de indivíduos, para a avaliação de seu desempenho e para a avaliação de suas necessidades de treinamento, como já discutimos.

A sugestão que se tentou oferecer neste texto é a de que as instituições de pesquisa, ao refletirem sobre a administração de sua atividade-fim, lancem mão dos conhecimentos já existentes, gerados pelas ciências sociais. Assim, estas instituições, além de fazerem do conhecimento científico seu fim, poderão também utilizá-lo como instrumento para administrar o processo pelo qual ele será produzido.

\section{REFERENCIAS BIBLIOGRÁFICAS}

Alves, E. R. A. O processo de geração de conhecimentos. In: Alves, Eliseu; Pastore, José \& Pastore, Affonso C., ed. Coletânea de trabalhos sobre a Embrapa. Brasília, Embrapa-DID, 1980a.
As unidades de difusão de tecnologia da Embrapa. In: Alves, Eliseu; Pastore, José \& Pastore, Affonso C., ed. op. cit. $1980 b$.

. O modelo institucional da Embrapa. 1n: Alves, Eliseu; Pastore, José \& Pastore, Affonso C., ed. op. cit. $1980 c$.

\& Pastore, J. Nova abordagem para a pesquisa agrícola. In: Alves, Eliseu; Pastore, José \& Pastore, Affonso C., ed. op. cit. 1980.

Borges-Andrade, J. E. Aprendizagem por observação: perspectivas teóricas e contribuições para o planejamento instrucional - uma revisão. Revista Psicologia: Ciência e Profissão, 1(2):2-68, 1981.

\& Lima, S. M. V. Avaliação de necessidades de treinamento:um método de análise de papel ocupacional. Brasília, Departamento de Recursos Humanos/Embrapa, 1982. reprogr.

coord.; Pereira, W. C. A; Carvalho, E. O. et alii. Subprojeto $A$ - Análise de cargos. In: Projeto de Reformulação do Plano de Cargos e Salários da Embrapa (Projeto Recargos). Brasília, Departamento de Recursos Humanos/Embrapa, 1980. reprogr.

Burns, T. Stalker, S. M. The Management of innovation. London, Tavistock, 1961.

Coqueiro, E. P. Treinamento de recursos humanos na Embrapa. In: Documentos, Brasília, Embrapa-DRH-DID, no3, 1981.

Dahrendorf, R. Homo sociologicus. In: Ensaio sobre a história, o significado e a critica da categoria e papel social. Rio de Janeiro, Tempo Brasileiro, 1969. 
Hage, J. Theories of organizations: form, process and transformation. New York, John Wiley, 1980.

The Application of organizational theory to the problem of agricultural research in Brazil. College Park, Md., Center for Innovation - Program on the Management of Research and Development, University of Maryland, 1982. reprogr.

\& Dewar, R. Elite values versus organizational structure in predicting innovation. Administrative Science Quarterly, 18: 274-90, Sept. 1973.

Katz, D. \& Kahn, R. Psicologia social das orgänizações. São Paulo, Atlas, 1978. cap. 7.

Lo Ré, V. A. M. Formação de equipes de trabalho em estruturas matriciais. In: Administração do processo de inovação tecnológica. São Paulo, Instituto de Administração/FEA/USP/Atlas, 1980.

Long, J.S. \& McGinnis R. Organizational context and scientific productivity. American Sociological Review, 46: 422-42, 1981.

Marcovitch, J. Desempenho organizacional na instituição de pesquisa aplicada. In: Administração do processo de inovação tecnológica. São Paulo, Instituto de Administração/FEA/USP/Atlas, 1980.

Maximiano, A.C. A. A função gerencial no processo de inovação tecnológica. In: Administração do processo ... op. cit.

Pastore, J. \& Alves, E. R. A. Reforming the Brazilian agricultural research system. In: Alves, Eliseu; Pastore, José \& Pastore, Affonso C., ed. Coletânea de trabalhos sobre a Embrapa. Brasilia, Embrapa-DID, 1980.

Pelz, D. C. \& Andrews. F. M. Scientists in organizations - productive climates for research and development. Ann Arbor, Mich., Institute for Social Research, The University of Michigan, 1976.
Pereira, W. C. A. Resolução de problemas criativos ativação da capacidade de pensar. Miscelânea, Brasília, Embrapa-DID, no 1, 1980.

Quinn, J. B. Budgeting for research. In: Heyel, Carl, ed. Handbook of industrial research management. 2. ed. New York, Reinhold Book, s. d.

Quirino, T. R. A Socialização ocupacional do pesquisador agropecuário. In: Documentos, Brasília, Embrapa/ DRH/DID, no 4, 1981.

Borges-Andrade, J.E. \& Pereira, W. C. A. Recursos humanos, conhecimento e tecnologia: avaliação do programa de pós-graduação da Embrapa no Brasil e sugestões de melhorias. In: Documentos, Brasília, Embrapa/DRH/DID, no 2, 1980.

\& Pereira, W. C. A. Referencial teórico para o Projeto de Reformulação do Plano de Cargos e Salários da Embrapa. In: Projeto de Reformulação do Plano de Cargos e Salários da Embrapa. (Projeto Recargos). Brasília, Departamento de Recursos Humanos/Embrapa, 1980. reprogr.

; Pereira, W. C. A. \& Borges-Andrade, J.E. Princípios de desenvolvimento de recursos humanos. In: Relatório de atividades - 1979 , coord. e redigido por Tarcizio Rego Quirino, Waldecyr Cavalcanti de Araújo Pereira e Jairo Eduardo Borges-Andrade. Brasília, Embrapa/DRH, 1980.

Schwartzman, S. Modelos de atividade científica. In: Schwartzman, Simon, coord. Administração da atividade cientifica. Brasília, Finep/CNPq, 1981.

Vasconcellos, E. Ambigüidade e divisão da autoridade na estrutura matricial. In: Administração do processo de inovação tecnológica. São Paulo, Instituto de Administração/FEA/USP/Atlas, 1980.

Vaz, Z. Princípios básicos da administração das ciências. In: Schwartzman, Simon, coord. Administração da atividade cientifica. Brasília, Finep/CNPq, 1981.

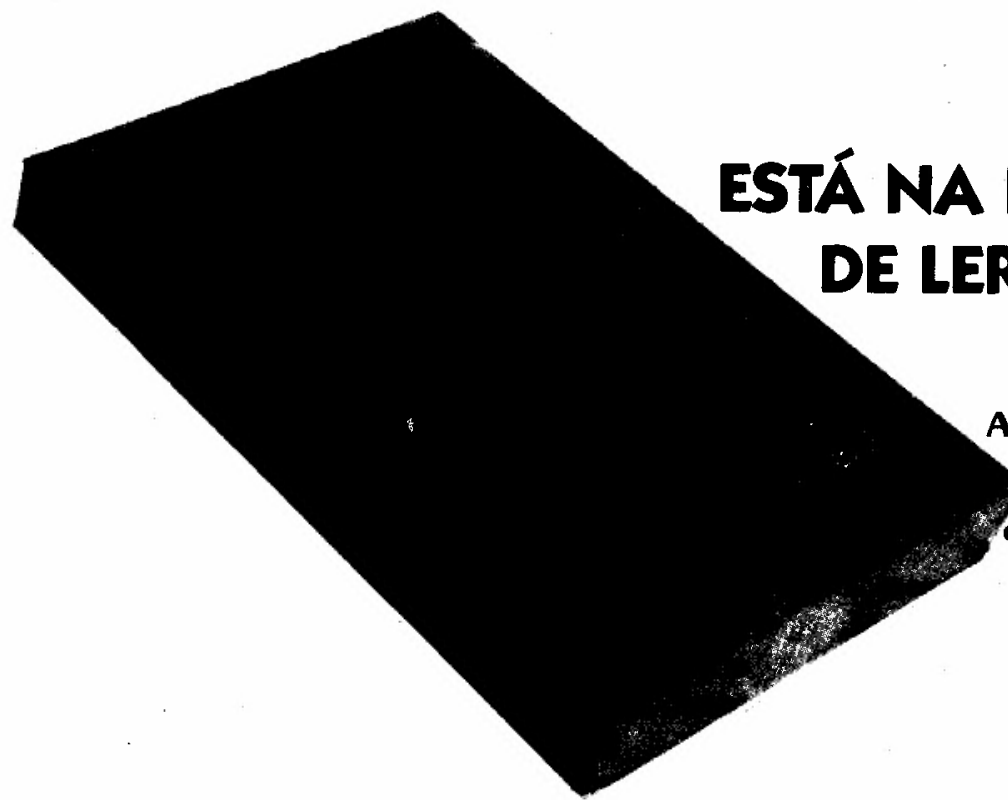

A ecologia do ponto de vista econômico, político e social. Uma obra fundamental para quem se interessa pela sobrevivência. 